\title{
DEVELOPMENT OF INITIAL MATERIAL FOR MARKER ASSISTED POTATO (Solanum tuberosum L.) PARENTAL LINE BREEDING AT THE DIPLOID LEVEL (review)
}

\section{A.P. YERMISHIN, E.V. VORONKOVA}

Institute of Genetic and Cytology of National Academy of Science of Belarus, 27, ul. Akademicheskaya, Minsk, 220072 Republic of Belarus, e-mail ermishin@igc.by, E.Voronkova@igc.by ORCID: Yermishin A.P. orchid.org/0000-0002-3106-4926

The authors declare no conflict of interests Received November 9, 2016

\section{Abstract}

It is important for improving the efficacy of potato breeding to have parental lines that are multiplex for many genes of agronomic characters, first of all genes of resistance to pests and diseases (that have two or more dominant alleles in the locus) (J.E. Bradshaw et al., 1994). Parental lines that are multiplex for several resistance genes occur not often (A.P. Yermishin et al., 2016) and, owing to biological peculiarities of potato crop, they can be produced only by means of breeding at the diploid level. In the presented review the genetic principles are described and an experience of their use by authors in research devoted to the development of the initial material applicable for effective marker assisted potato parental line breeding at the diploid level. The material includes the collection of initial dihaploids originated from potato varieties which were selected for viability, tuber performance, cultivar characters and DNA-markers of pest and diseases resistance genes; the diploid breeding material having wide range of late blight and virus resistance genes, introgressed from wild potato species by means of original methods of overcoming interspecific reproductive barriers; the diploid lines - donors of self-incompatibility gene and high male fertility genes that are effective as in heterozygous as well as in homozygous condition; the diploid lines - donors of genes of male fertile FDR (first division restitution) $2 n$-gamete formation. The best diploid lines having a complex of pest and diseases resistance genes, selected as the result of diploid breeding (on the basis of initial dihaploids, interspecific hybrids and donors of fertility) were used for production of multiplex tetraploid parental lines by means of mitotic chromosome doubling. Diploid parental lines suitable for hybridization with potato varieties (for meiotic polyploidization) were bred using lines-donors of genes of male fertile FDR $2 n$-gamete formation. The diploid initial material developed as the result of the research is of the interest for prospective alternative directions of potato breeding using selection at the diploid level: breeding diploid potato varieties as well as parental lines for production of hybrids and hybrid populations for true potato seed technology.

Keywords: potato, breeding at the diploid level, marker-assisted selection (MAS), multiplex parental lines, male fertility, unreduced gametes

The approach based on development of hybrid populations of high selective value, i.e. hybrid populations where genotypes meeting the requirements to potato varieties are observed more frequently, as compared to random crossings, is considered as the most promising for more effective potato breeding. Such hybrid populations are developed using the known breeding lines with high combining ability with regard to productivity indices, as well as disease and pest resistance gene complex, as one or both parental lines. It is imperative that these breeding lines are multiplex (i.e. having two or more dominant alleles) for several agriculturally valuable genes (first of all, disease and pest resistance genes) [1].

Parental lines that are multiplex for several resistance genes are uncommon among the existing varieties [2]. Owing to biological peculiarities of potato crop, a vegetatively reproduced autotetraploid, effective selection of parental lines that are multiplex for several resistance genes is only possible 
by means of breeding at the diploid level.

More simple inheritance of valuable traits at the diploid level makes selection of hybrids with a set of required characteristics much easier, as compared to the tetraploid level. Application of DNA markers allows increasing the effectiveness of diploid selection significantly. Genotypes selected for a complex of resistance gene markers, as well as productivity indices and cultural traits of plants and tubers, may be transferred to the tetraploid level by means of mitotic duplication. As a result, tetraploid parental lines with a complex of genes observed in initial dihaploids are obtained. At that, they are duplex for the respective genes in case of heterozygous dihaploids and quadruplex in case of duplication of chromosomes in homozygotes.

Development of diploid parental lines able to form fertile unreduced pollen by combined selection at the diploid level is considered promising. Their use in crosses with tetraploid varieties allows obtaining of uniform productive environmentally sustainable tetraploid hybrid populations [3], which are mainly not subject to segregation for a complex of traits formed at the diploid level.

Initial breeding material for effective breeding at the diploid level is required for development of the said parental lines. It shall include the collection of dihaploids characterized by a broad genetic basis, sufficient fertility and mutations related to formation of unreduced gametes, which is important for development of diploid parental lines. This material is not available to the majority of potato breeding companies and gene banks. This paper describes the underlying genetic principles of initial material development for diploid potato breeding, as well as the experience of their practical use in research by the authors.

Development of potato dihaploids. Haploids obtained from tetraploids $(2 n=4 \times=48)$ are referred to as dihaploids $(2 n=2 \times=24)$, while haploids obtained from diploids $(2 n=2 \times=24)$ are referred to as monoploids or monohaploids $(2 n=\times=12)$. Therefore, for potato the term "dihaploid" does not correspond to the term "doubled haploid" used in genetics of diploid plant species.

Pollination of tetraploid varieties or breeding clones with pollen of haploproducers Solanum phureja Juz. \& Bukasov is the main method of development of potato dihaploids. Pseudogamy and parthenogenesis are cytological mechanisms of dihaploid embryo development [4]. During pollination with $S$. phureja pollen both nuclei $(n=\times=12)$ of the pollen grain merge with the central nucleus of $S$. tuberosum embryo sac $(2 n=4 \times=48)$, which leads to formation of hexaploid endosperm. The egg nucleus $(n=2 \times=24)$ remains unfertilized, but is induced to differentiation. There is evidence [5] of another mechanism responsible for formation of dihaploids which may take place by means of selective $S$. phureja chromosome elimination during formation of hybrid embryos.

Dutch forms of $S$. phureja, IvP 35, IvP 48 and IvP 101, combining high ability to produce haploids with homozygous state of the embryo-spot marker gene responsible for seed lobe anthocyanin coloring, are the most widely used in potato breeding [6]. The embryo-spot is easily detected by a binocular microscope, so introduction of the said haploproducers in the breeding practice made it possible to identify potato dihaploids (by absence of a marker trait) with minimum labor effort. Dihaploids selected from the progeny obtained by pollination of tetraploid varieties or breeding clones with pollen of haploproducers are referred to as primary dihaploids, and the breed obtained by their crossings - as secondary dihaploids.

Studies on selection at the diploid level in potato breeding have been conducted in the potato genetics laboratory of the Genetics and Cytology Institute of the National Academy of Sciences of Belarus since early 1990-s, based 
on the material provided by S.A. Lyorek (Ukrainian Research Institute of Potato Cultivation, Kyiv region). During this period a comprehensive collection of diploid breeding material has been developed, which included laboratory primary potato dihaploids, secondary dihaploids on their basis, as well as secondary dihaploids obtained from other research teams. In view of development of DNA markers to detect disease and pest resistance genes in potato, we have been tasked with improvement of quality of the collection by creation of new primary dihaploids with maximum diversity and high frequency of resistance gene markers.

Characteristics of potato varieties of various origins from catalogues have been studied, and varieties, the description of which suggested the presence of several disease and pest resistance genes in the genome, have been selected. The presence of certain genes was confirmed using the respective DNA markers. About 100 of primary dihaploids for several varieties and valuable breeding clones have been obtained using $S$. phureja IvP 35 haploproducer. Some DNA markers observed in initial varieties were lost during transfer to the diploid level due to segregation. However, the frequency of the majority of analyzed markers in the primary dihaploid population obtained turned out to be sufficiently high [7]. New dihaploids of potato varieties, preliminarily evaluated with regard to presence of DNA markers of disease and pest resistance genes, are added to the collection every year. The best dihaploids (apart from DNA markers, viability, tuber performance, nest size, tuber shape, eye depth, and flowering capacity are considered) are included in the program of crossings with diploid lines, which are fertility and $2 n$-pollen formation gene donors, as well as donors of new blight and virus resistance genes introgressed by us into diploid breeding material from wild species.

Diploid breeding material with blight and virus resistance genes introgressed from wild species. More effective involvement of wild and primitive cultivated potato species in valuable gene pool breeding is one of important benefits of selection at diploid level, as compared to tetraploid level. About $70 \%$ of known wild and cultivated potato species are diploids, many of which can be crossed with $S$. tuberosum dihaploids rather successfully. More simple inheritance at the diploid level in backcross generations of interspecies hybrids allows more quick and less expensive selection for certain genes, concentration of desirable and elimination of undesirable wild specie genes [8].

Our study on remote potato hybridization focused on interspecies reproductive barrier mechanisms and effective methods for their overcoming to introgression into breeding material of valuable genes from wild species, which normally do not cross with cultivated potato. At that, achievements in development and implementation of prezygotic incompatibility overcoming approaches, based on the use of segregation for S-genes of parental species, shall be noted. As a result, we involved the tetraploid somatic hybrids of $S$. tuberosum dihaploids with Mexican diploid wild species $S$. bulbocastanum and $S$. pinnatisectum in breeding program [9, 10]. Additionally, we have shown that wild diploid potato species $S$. verrucosum and its laboratory $S v S v$-lines deficient on pistillate S-RNAses, could be successfully used for overcoming pre- and postzygotic incompatibility at interspecies crossing. The use of $S$. verrucosum and $S v S v$-lines allowed involvement of $S$. bulbocastanum, S. pinnatisectum, S. polyadenium, S. circaeifolium, and $S$. commersonii in breeding, as well as overcoming of unilateral incompatibility common to allotetraploid wild species [11-14]. We also observed a new phenomenon, i.e. development of diploid hybrids in crossings of allotetraploid wild potato species $S$. acaule, $S$. stoloniferum, $S$. fendlery, and $S$. polytrichon with $S$. tuberosum dihaploids. Development of such hybrids may greatly simplify the use of allotetraploid species in breeding valuable gene pool [15, 16]. Application of the 
above mentioned methods resulted in unique diploid breeding material with a complex of genes of high long-term resistance to blight and viruses [17, 18].

Development of fertility gene donors. It is believed that transfer from the tetraploid level to the diploid level during development of potato dihaploids by self-pollination takes about three generations [19]. As a result, viability of dihaploids mostly decreases and development delays compared to initial varieties. Sterility or decreased fertility is one of the key manifestations of inbreeding depression in primary dihaploids.

About one half of $S$. tuberosum dihaploids developed have rather active flowering required for their inclusion in hybridization. However, flowering genotypes can only be used as female parents, as the majority of male plants is sterile [20]. Though female fertility (ability to set berries and seeds after pollination with fertile pollen of compatible pollinators) is decreased in S. tuberosum dihaploids, as compared to tetraploids, it is not considered as the main limiting factor in crossings with dihaploids [21].

Primary potato dihaploids with viable pollen, which could be visualized by acetocarmine staining, cannot mainly serve as pollinators in crossings as their pollen is functionally inactive. Fertility evaluated by the results of hybridization is referred to as "functional male fertility" (FMF) [22]. FMF is determined both by the total amount of pollen and its proportion capable of delivery of male gametes to the embryo sac, i.e. functionally fertile pollen. Several methods are helpful for indirect evaluation of functional pollen fertility (FPF) [23]. According to our experience, the determination of germinated pollen grains abundance on growth medium during a certain period is the most acceptable [24].

The fertility in $S$. tuberosum dihaploids is determined by the initial tetraploid form index and inbreeding [8]. Selection against recessive alleles unfavorable for male fertility is normally not performed in tetraploid potato varieties, as sterile forms may be used as female parents in breeding. Upon development of dihaploids they pass to homozygous state, which is manifested in a decrease in fertility and appearance of sterile forms. Estimates of male fertility in doubled monoploid are in favor of hypothesizing inbreeding as the main reason of male sterility in potato dihaploids [25]. Hybridization of dihaploids with primitive cultivated and wild diploid potato species, which eliminates the inbreeding depression effect, contributes to recovery of their fertility [8]. However, several cycles of crossing at the diploid level are required for development of parental lines suitable for use in potato variety breeding. The genotypes with decreased functional pollen fertility predominate during hybridization of secondary potato dihaploids, especially in combinations with sterile and low-fertility forms [26].

Sterile male progenies are frequent at $S$. tuberosum dihaploids hybridization with diploid potato species. This is due to genetic and cytoplasmatic male sterility, resulting from interaction of dominant nuclear genes observed in the majority of South American diploid species and $S$. tuberosum cytoplasmatic genes [27]. Origin of primary dihaploids from potato varieties carrying certain types of wild specie cytoplasm may also serve as a factor responsible for male sterility. For example, the presence of D cytoplasm from $S$. demissum in varieties correlates to functional pollen sterility, and the presence of $\mathrm{W} / \gamma$ cytoplasm, e.g. from $S$. stoloniferum, correlates to formation of completely abortive pollen [28].

Hybridization of potato dihaploids may fail due to self-incompatibility, which may become a substantial obstacle for implementation of breeding programs related to the use of self-pollination, inbreeding or backcrossing. Solanum diploid species are characterized by gametophytic self-incompatibility which is manifested in inhibition and stasis of pollen tubes in the upper third of pistil column [11]. 
Examination of allelic diversity of potato S-genes has demonstrated its significant limitation [29]. The data obtained in our laboratory suggest that the results of hybridization of certain $S$. tuberosum dihaploids may be explained by the fact that they contain no more than four S-alleles. At that, up to three common $\mathrm{S}$-alleles may be observed in dihaploids originating from two unrelated tetraploid potato varieties [30]. The use of diploid breeding lines with self-compatibility mutations in crossings may contribute to avoiding this problem. Self-compatibility mutations have been identified in $S$. $t u$ berosum dihaploids [31] and in some diploid potato species ( $S$. goniocalix, S. kurzianum, S. neohawkesii, S. phureja, S. pinnatisectum, S. raphanifolium, $S$. sanctae-rosae, S. stenotomum) [32]. The mutations $t S 1$ in $S$. tuberosum dihaploids [31] and Sli in S. chacoense [33] are best known genetically. Sli homozygous donors were successfully used for breeding of diploid inbred lines intended for future development of heterotic hybrids on their basis [34].

The program for development of fertility donors proposed by our laboratory allows solving the problem of decreased fertility in diploid potato plants. This program includes the combination of inbreeding used to eliminate alleles unfavorable for fertility, and hybridization between high fertile genotypes aimed at replacement of unfavorable alleles with alleles that affect pollen development process in potato positively [35].

As a result of examination of a large secondary potato dihaploids collection, IGC 203/5.7 clone based on Polesskii rozovii variety dihaploid and $S$. phureja $\times S$. vernei hybrid has been isolated. This clone is male fertile and selfcompatible (genetic analysis has demonstrated simple single gene inheritance of this self-compatibility mutation). IGC 203/5.7 clone was involved in hybridization with high fertile forms IGC 92/1.1 and IGC 92/1.2 selected from breed of open pollination of Jubel variety primary dihaploids, which were used as fertility gene donors. The most fertile forms were selected from the obtained hybrids and further IGC 92/1.2 backcross generations (primarily for FPF indices), i.e. mild increase in homozygosity was used, as self-pollination and sibbing produced strongly inbred sterile progeny with low viability. As a result, several high fertile secondary dihaploids have been received to be used for increase in male fertility of initial diploids [35].

Hybridization of male sterile potato dihaploids with fertility donors obtained ensures fertile progeny which can be used effectively in MAS at diploid level. For example, for IGC 01/59.11 line the frequency of high fertile hybrids in the Alpinist variety primary dihaploid progeny amounted to 100 $\%$, and in the Nortena variety dihaploid progeny to $53 \%$ [36]. Currently we use high fertile clones of IGC 10/1.n hybrid population (it was developed in 2010 by self-pollination of IGC 01/61.40 fertility donor line) as fertility gene

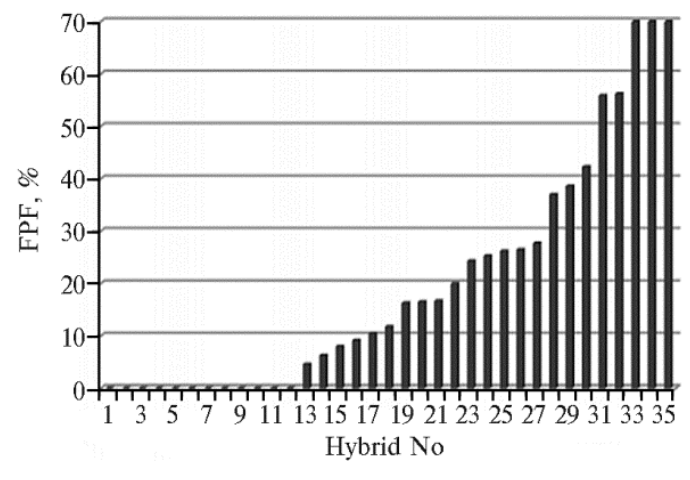

Fig. 1. Functional pollen fertility (FPF) in hybrids among high fertility diploid potato clones IGC 10/1.1 and IGC 10/1.23. Despite of similar origin of parental forms (obtained as a result of self-pollination of a relatively homozygous diploid line, the fertility donor IGC $01 / 61.40$ ), more than half of hybrids is characterized by high $(>10 \%)$ FPF.

donors in crossings with primary dihaploids. These clones ensure development of fertile hybrids both in crossings with primary dihaplo- 
ids, when fertility genes are heterozygous, and in crossings with each other, when fertility genes are homozygous (Fig. 1).

Thus, hybridization between fertility donors and primary dihaploids selected for viability, productivity, cultivation parameters and a complex of disease and pest resistance gene markers provides initial forms, suitable for breeding for these traits at diploid level. Sufficient male fertility can be easily maintained during such breeding by inclusion of genes with high FPF in hybridization. Effective multiplex tetraploid parental lines can be developed on the basis of the best diploid lines by mitotic chromosome duplication.

Development of diploid parental lines producing unreduced pollen requires slightly different initial forms. Genotypes selected for a complex of agronomically valuable traits shall be suitable for meiotic duplication of chromosomes. According to our experience, FPF and the proportion of $2 n$-pollen shall be at least $10 \%$. Such genotypes shall appear during final stages of diploid breeding with rather high frequency. It is believed that frequency of genotypes forming unreduced gametes among dihaploids and diploid potato species is sufficient for successful meiotic polyploidization [8]. However, our long-term studies of the large collection of secondary potato dihaploids of various origins suggest that the proportion of genotypes forming fertile unreduced pollen amounted to as few as $0.8 \%$ of the total number of analyzed forms [35], which is clearly insufficient for successful breeding for a complex of traits.

Development of unreduced gamete formation gene donors. Unreduced $2 n$ gametes with the number of chromosomes of sporophyte, but not a gametophyte, may be due to meiotic disturbances. Several types of such disturbances resulting in formation of $2 n$ gametes are currently known. First division restitution (FDR) mechanism is of the greatest importance for breeding of diploid parental lines of potato.
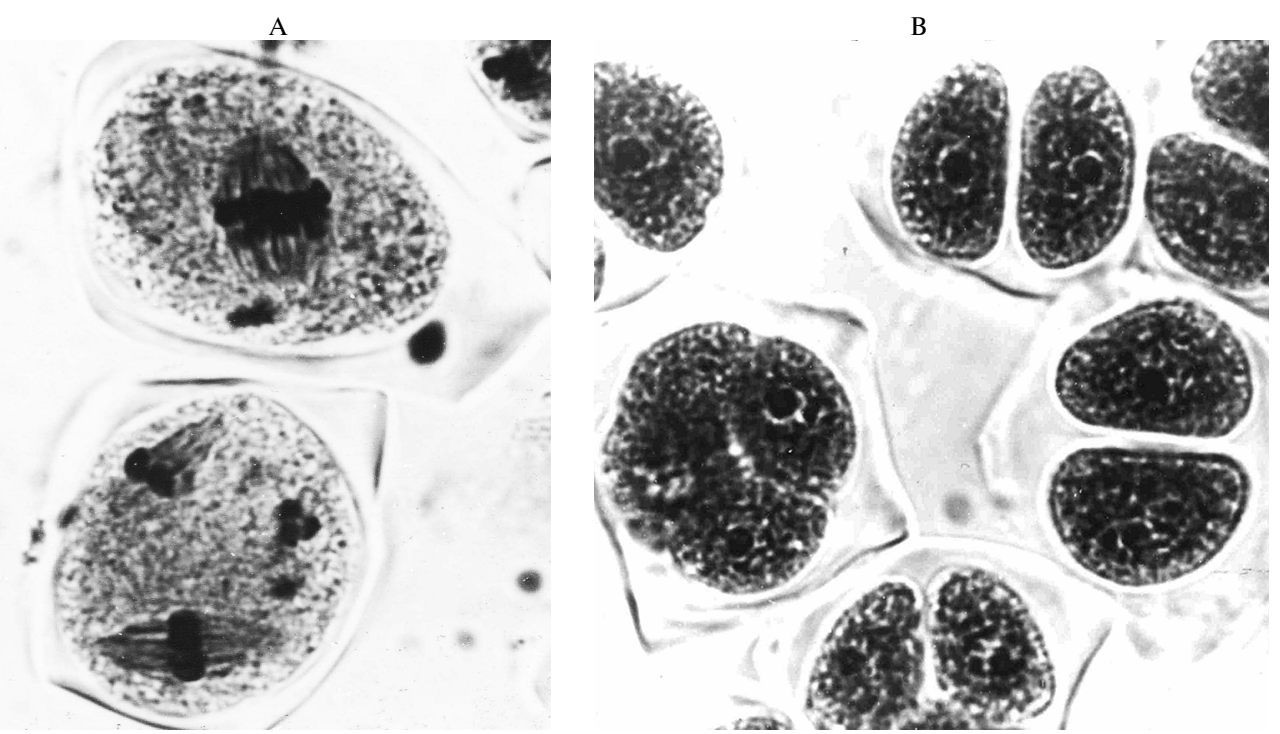

Fig. 2. Meiotic disturbances in potato dihaploids (Solanum tuberosum L.) related to formation of unreduced FDR (first division restitution) gametes: A - merged spindles in the second meiotic division due to manifestation of $f_{S}$ mutation (top) and two spindles at normal meiosis (bottom); B - formation of $2 n$-microspore dyads as a result of meiotic disturbances related to $f s$ mutations (bottom left - normal tetrad of $n$-microspores) (photo by courtesy of V.E. Podlisskykh).

FDR is associated with the occurrence of merged $(f s)$ [37] or parallel (ps) [39] spindles in metaphase II. Only two poles with two chromosome groups and only one equational division cell wall are formed in mutant cells as a result 
of the second meiotic division, which leads to formation of $2 n$ microspore dyad (Fig. 2). A special study of the role of spindle coordination in FDR has been conducted in our laboratory. Examination of correlations between $p s$ frequency and the frequency of dyads in the forms which produce and do not produce $2 n$ pollen, with the use of mathematical modeling, has provided evidence that parallel spindles do not result from meiotic disturbances, and dyad formation is related to $f s$ mutation [39]. In case of FDR, chromatids of each chromosome enter different $2 n$ spores ensuring preservation of parental heterozygosity in the formed gametes (average degree of parental heterozygosity in FDR gametes is up to $80 \%$ ) [40]. It should be noted that one chromatid of each of 24 chromosomes involved in recombination during the first meiotic division, enters $2 n$ spores. Thus, all dominant alleles of disease and pest resistance genes observed in unreduced pollen producer are presented in each of them.

The presence or absence of spindle merging during meiosis and formation of $2 n$ pollen is a qualitative trait manifested quantitatively. The frequency of $2 n$ pollen formation in plants in natural populations of potato species and in breeding samples varies widely, from a fraction to $100 \%$ [38]. Expressivity of $f_{s}$ genes manifested as a frequency of $2 n$ pollen is determined by the genotype, environmental factors and their interaction [41]. A model of $f s$ genetic control has been proposed, where the main genes (gene) interact with polygenes which make a genetic context modifying expression of the main genes [42]. Quantitative trait analysis has demonstrated that the frequency of $2 n$ pollen ( $f s$ expressivity variation) is determined by $2-4$ loci with similar effects [43]. The $2 n$ pollen rate increases during recurrent selection [44]. Using this approach, we have developed diploid potato lines with $80-100 \%$ of $2 n$ pollen [35].

Summarizing our studies on genetic control of unreduced pollen formation during hybridization of potato dihaploids [45], it should be noted that, firstly, the possibility of segregation of hybrids capable of unreduced pollen formation during crossing of dihaploids which do not produce $2 n$ pollen is extremely low. At that, the frequency of dyads in hybrids forming unreduced pollen is usually low and insufficient for meiotic duplication of chromosomes. Secondly, crossings where both parents form unreduced pollen ensure development of hybrids, a certain proportion of which forms $2 n$ pollen with the frequency sufficient for meiotic duplication. The higher is the unreduced pollen frequency in each parent, the higher is this proportion. Development of hybrids forming $2 n$ pollen with higher frequency, as compared to the parent with the best characteristics, is possible. Thirdly, hybridization between dihaploids, one of which produces $2 n$ pollen with the frequency of 80-100\% (donor of genes of the trait), while the other does not produce it, does not ensure prodgeny capable of unreduced pollen production with the frequency sufficient for meiotic duplication of chromosomes. A small amount of such hybrids can only be developed in case of presence of genotypes producing $2 n$ pollen in the parentage of a parent with normal meiosis.

Thus, in order to identify genotypes capable of functionally fertile unreduced pollen formation with the frequency sufficient for meiotic duplication of chromosomes (along with a complex of agronomically valuable traits) during the final diploid breeding, both parents shall have genes of this trait. So, genes responsible for $2 n$ pollen formation shall be introduced in the genetic pool of breeding forms at early diploid breeding. To do so, lines which act as donors of fertility genes and formation of unreduced gametes of a certain type (FDR based on $f s$ mutation) at the same time are required. The fertility donor lines developed by us normally do not form $2 n$ pollen. In order to develop donor lines for 
fertility genes and $2 n$ gamete formation the fertility donors were involved in hybridization with the above mentioned lines, capable to produce FDR $2 n$ pollen at high frequency (80-100\%) due to $f s$ mutation. As a result, several hybrids with high FPF and $2 n$ pollen frequency of 20-40 \% were selected. They can successfully pollinate both primary and secondary dihaploids, as well as tetraploid varieties and breeding clones [2].

According to the program of breeding diploid parental lines, forming fertile unreduced pollen, donors of fertility and $2 n$ gametes were crossed with primary dihaploids possessing a complex of disease and pest resistance genes. As per results of tests in 2015-2016 several promising seedlings have been selected, combining high productivity (at the level of reference varieties), agronomical traits, and presence of markers to several disease and pest resistance genes, which are male fertile and capable of unreduced pollen formation. For example, in 201543.2 $\%$ of seedlings selected for productivity formed functionally fertile pollen, and some of them produced $2 n$ gametes (most of them had $2 n$ pollen producers in the parentage). This allowed us to identify a sufficient number of pollinators for MAS program for breeding parental lines at the diploid level (Table).

Characteristic of some diploid potato hybrids (Solanum tuberosum L.) selected for use as pollinators in marker-mediated breeding of parental lines at the diploid level

\begin{tabular}{|c|c|c|c|c|c|c|c|c|c|}
\hline \multirow[b]{2}{*}{$\begin{array}{l}\text { Hybrid, } \\
\text { variety }\end{array}$} & \multicolumn{2}{|c|}{ Tubers per plant } & \multirow[b]{2}{*}{$\begin{array}{l}\text { Average } \\
\text { tuber } \\
\text { weight, g }\end{array}$} & \multirow[b]{2}{*}{$\begin{array}{l}\text { FPF, } \\
\%\end{array}$} & \multirow[b]{2}{*}{$\begin{array}{l}2 n \text { pollen } \\
\text { frequen- } \\
\text { cy, } \%\end{array}$} & \multicolumn{4}{|c|}{ DNA markers to resistance genes } \\
\hline & weight, $\mathrm{g}$ & $\begin{array}{l}\text { number, } \\
\text { pcs }\end{array}$ & & & & $\begin{array}{l}H 1 \\
\text { TG689 } \\
{[46]}\end{array}$ & $\begin{array}{l}\text { Gro 1-4 } \\
\text { Gro 1-4 } \\
{[47]}\end{array}$ & $\begin{array}{l}\text { Ryadg } \\
\text { RYSC3 } \\
{[48]}\end{array}$ & $\begin{array}{l}\text { Sen 1 } \\
\text { N125 } \\
{[47]}\end{array}$ \\
\hline $\mathrm{GC} 12 / 42.1$ & $902.3 \pm 107.8$ & $18.5 \pm 2.6$ & $57.9 \pm 15.3$ & 25.8 & 11.0 & 0 & 1 & 1 & 0 \\
\hline IGC $12 / 43.3$ & $838.2 \pm 156.4$ & $14.6 \pm 1.9$ & $62.1 \pm 13.3$ & 49.5 & 0 & 1 & 0 & 1 & 0 \\
\hline IGC $12 / 48.2$ & $802.0 \pm 122.7$ & $22.0 \pm 3.2$ & $36.5 \pm 1.5$ & 47.2 & 0 & 1 & 0 & 1 & 1 \\
\hline IGC $12 / 42.5$ & $672.0 \pm 137.9$ & $16.7 \pm 3.4$ & $44.5 \pm 6.2$ & 44.6 & 16.0 & 0 & 1 & 1 & 0 \\
\hline 2 & $573.7 \pm 110.9$ & $14.3 \pm 2.4$ & 40.0 & 10 & 9 & 0 & 0 & 1 & 0 \\
\hline 42.3 & $529.5 \pm 92.3$ & $10.5 \pm 1.2$ & 50. & 56 & & 0 & 1 & 1 & 0 \\
\hline [GC $12 / 45.11$ & $453.0 \pm 95.3$ & $16.5 \pm 3.3$ & $28.0 \pm 2.3$ & 14.0 & 5. & 0 & 1 & 1 & 0 \\
\hline IGC $12 / 45.12$ & $379.5 \pm 54.9$ & $20.2 \pm 1.9$ & $19.0 \pm 2.37$ & 21.3 & 10.0 & 0 & 1 & 1 & 1 \\
\hline Lilea & $651.6 \pm 93.1$ & $6.9 \pm 0.7$ & $88.8 \pm 8.3$ & & & 1 & 1 & 0 & 1 \\
\hline Skarb & $894.3 \pm 152.8$ & $14.2 \pm 1.3$ & $61.3 \pm 7.7$ & & & 1 & 0 & 0 & 0 \\
\hline Ragneda & $1137.7 \pm 216.9$ & $16.8 \pm 2.3$ & $59.7 \pm 7.4$ & & & 1 & 0 & 0 & 1 \\
\hline \multicolumn{10}{|c|}{$\begin{array}{l}\text { N ot e. Average values for } 2015-2016 \text { are presented for hybrid productivity, in triplicate, reference variety tubers } \\
\text { (early Lilea variety, mid-ripening Skarb variety and middle-late Ragneda variety) in } 2015 \text { were planted as a single } \\
\text { block, in } 10 \text { replications, in } 2016-\text { as three randomized blocks of three plants each }(X \pm S E M \text {; experimental field } \\
\text { of the Genetics and Cytology Institute of the National Academy of Sciences of Belarus, Minsk). Functional pollen } \\
\text { fertility (FPF) was evaluated as described [24]. Pollen with the diameter above } 26 \mu \text { mas considered as unre- } \\
\text { duced ( } 2 n \text { ) (as per cytological preparations stained with } 2 \% \text { acetocarmine). Formation of } 2 n \text { pollen was not exam- } \\
\text { ined in standards (blank spaces in the table). " } 1 \text { " and "0" - the marker is present or absent, respectively. }\end{array}$} \\
\hline
\end{tabular}

Thus, the breeding material developed has all properties required for MAS at diploid level with development of valuable genotypes, suitable for meiotic duplication at the final stage of diploid breeding.

The prospects of use of marker-mediated selection at the diploid level in potato breeding. The diploid breeding forms developed by us is primarily intended for creation of diploid and tetraploid parental lines, the use of which will significantly increase the effectiveness of conventional breeding. However, it is also of interest for prospective alternative breeding using selection at diploid level. The first trend is breeding of diploid varieties. The best diploid hybrids are equal to potato varieties in productivity and a complex of traits, and breeding at the diploid level is much more effective as compared to the tetraploid level. The second trend means a development of hybrids or hybrid populations reproduced by true seeds. These may include diploid hybrids from crossing of homozygous parental lines, hybrid diploid populations from crossing of relatively homozygous diploid parental lines, and hybrid tetraploid populations from crossing of diploid parental lines, which form unreduced pollen, with potato varieties. 
Reproduction of potato by true potato seeds (TPS) suggests the use of seeds obtained from self-pollination (open pollination) of a variety (parental line) or from hybridization of specially selected varieties (parental lines) instead of tubers. A biennial cultivation scheme is also possible, i.e. tubers are obtained from seed sowing on the first year and then used next year as planting material for commercial yield. Such tubers a smaller in size compared to ordinary seed tubers, and are much more healthy, as there is not enough time for accumulation of pathogens. These trends are considered promising for tropical countries where climate is unfavorable for potato seed breeding, and farmers are not able to purchase imported seed tubers annually and store them, reproducing independently [49].

The task of breeding for TPS technology is to obtain seeds of populations with uniform productivity and the presence of pathogen resistance genes, first of all, virus and blight resistance ones. Conventional approaches, i.e. selfpollination of varieties or intervarietal hybridization, did not match the expectations [49]. However, according to the data provided herein, the problems can be successfully solved by MAS at diploid level with respective diploid parental forms capable or incapable of production of unreduced gametes. It should be noted that TPS technology based on diploid hybrids from crossing homozygous parental lines has been recently considered the most promising for developed countries and capable of drastically change of the existing potato farming system [34, 50]. KWS SAAT SE (Germany), one of the world's largest breeding companies, has made a decision to focus its activities in potato breeding on development of this particular technology [51].

Thus, the use of diploid level selection in potato breeding for development of effective parental lines requires special parental forms. Apart from a broad range of primary dihaploids of various origins, carrying DNA markers to disease and pest resistance genes, and interspecies hybrids with valuable traits, diploid lines which can serve as fertility, self-compatibility and FDR $2 n$ pollen formation donors must be involved in crossing. They play a key role in diploid potato breeding, as they may help to obtain hybrid populations with fertility sufficient for effective selection at the diploid level.

\section{REFERENCES}

1. B radshaw J.E., Mackay G.R. Breeding strategies for clonally propagated potatoes. In: Potato genetics. J.E. Bradshaw, G.R. Mackay (eds.). CABI, Wallingford (UK), 1994: 109-132.

2. Ermishin A.P., Svitoch O.V., Voronkova E.V., Gukasyan O.N., Luk s h a V.I. Genetika, 2016, 5: 569-578 (doi: 10.7868/S0016675816050052) (in Russ.).

3. Ortiz R., Peloquin S.J., Freyre R., Iwa nag a M. Efficiency of potato breeding using FDR 2n gametes for multitrait selection and progeny testing. Theor. Appl. Genet., 1991, 82(5): 602-608 (doi: 10.1007/BF00226797).

4. Montelongo-Es cobedo H., Rowe P.R. Haploid induction in potato: sytological basis for the pollinator effect. Euphytica, 1969, 18: 116-123 (doi: 10.1007/BF00021990).

5. Clulow S.A., Wilkinson M.J., Waugh R., Baird E., D e Maine M.J., Powell W. Cytological and molecular observations on Solanum phureja-induced dihaploid potatoes. Theor. Appl. Genet., 1991, 82: 545-551 (doi: 10.1007/BF00226789).

6. Hermsen J.G.Th., Verdenius J. Selection from Solanum tuberosum group Phureja of genotypes combining high frequency haploid induction with homozygosity for embryo-spot. $\mathrm{Eu}$ phytica, 1973, 22: 244-259 (doi: 10.1007/BF00022632).

7. Voronkova E.V., Luksha V.I., Gukasyan O.N., Savchuk A.V., Ermishin A.P. Kartofelevodstvo (Minsk), 2011, 19: 215-226 (in Russ.).

8. J a n s k y S.H., P e 1 o qu i n S.J., Y e r k G.L. Use of potato haploids to put $2 \times$ wild species germplasm in usable form. Plant Breeding, 1990, 104: 290-294 (doi: 10.1111/j.14390523.1990.tb00438.x).

9. Ermishin A.P., Makhan'ko O.V., Voronkova E.V. Genetika, 2006, 42(12): 1674-1682 (doi: 10.1134/S1022795406120088) (in Russ.).

10. Ermishin A.P., Makhan'ko O.V., Voronkova E.V. Genetika, 2008, 44(5): 645-653 
(doi: 10.1134/S1022795408050086).

11. Ermishin A.P. Izvestiya NAN Belarusi, ser. biol. nauk, 2001, 3: 105-118 (in Russ.).

12. Polyukhovich Yu.V., Makhan'ko O.V., S avchuk A.V., Voronkova E.V., Ermishi n A.P. Izvestiya NAN Belarusi, ser. biol. nauk, 2010, 2: 51-58 (in Russ.).

13. Yermishin A.P., Polyukhovich Y.V., Voronkova E.V., Savchuk A.V. Production of hybrids between 2 EBN bridge species Solanum verrucosum and 1 EBN diploid potato species. Amer. J. Potato Res., 2014, 91: 610-617 (doi: 10/1007/s12230-014-9385-9).

14. Polyukhovich Yu.V., Voronkova E.V., S avchuk A.V., Ermishin A.P. Kartofelevodstvo (Minsk), 2013, 21(1): 136-145 (in Russ.).

15. Voronkova E.V., Lisovskaya V.M., Ermishin A.P. Genetika, 2007, 43(8): 1065-1073 (doi: 10.1134/S1022795400708008X) (in Russ.).

16. Ermis hin A.P. Izvestiya NAN Belarusi, ser. biol. nauk, 2014, 1: 23-31 (in Russ.).

17. Voronkova E.V., Lisovskaya V.M., Pavlyuchuk N.V., Savchuk A.V., Ermis hi n A.P. Kartofelevodstvo (Minsk), 2008, 14: 144-152 (in Russ.).

18. Voronkova E.V., Polyukhovich Yu.V., Savchuk A.V., Gukasyan O.N., Ermis hi n A.P. Molekulyarnaya i prikladnaya genetika (Minsk), 2013, 15: 104-110 (in Russ.).

19. Yeh B.P., Peloquin S.J., Hougas R.W. Meiosis in Solanum tuberosum haploids and haploid-haploid F 1 hybrids. Can. J. Genet. Cytol., 1964, 6: 393-402 (doi: 10.1139/g64-050).

20. Carroll C.P., Low R.J. Flowering behavior and seed fertility in dihaploid Solanum tuberosum. Potato Res., 1975, 18: 416-427 (doi: 10.1007/BF00023782).

21. Trognitz B.R. Female fertility of potato (Solanum tuberosum ssp. tuberosum) dihaploids. Euphytica, 1995, 81(1): 27-33 (doi: 10.1007/BF00022456).

22. Carroll C.P., Low R.J. Aspects of male fertility in group Tuberosum dihaploids. Potato Res., 1976, 19: 109-121.

23. Trognitz B. R. Comparison of different pollen viability assays to evaluate pollen fertility of potato dihaploids. Euphytica, 1991, 56(2): 143-148 (doi: 10.1007/BF00042057).

24. Pallais N., Fong N., Berrios D. Research on the physiology of potato sexual seed production. Proc. Int. Conf. "Innovative methods for propagating potatoes». CIP Rep. 28th Planning Conf. Lima, CIP, 1984: 149-168.

25. M'Ribu H.K., Veilleux R.E. Fertility of doubled monoploids of Solanum phureja. Am. Potato J., 1992, 69(7): 447-459 (doi: 10.1007/BF02852295).

26. Ermishin A.P., Voronkova E.V. Izvestiya NAN Belarusi, ser. biol. nauk, 1998, 3: 45-52 (in Russ.).

27. Grun P. Evolution of the cultivated potato: a cytoplasmic analysis. In: The biology and taxonomy of the Solanaceae. Linnean Soc. Symp. Ser. № 7. Acad. Press, London, 1979: 655-665.

28. S a ne to mo R., Gebhard t C. Cytoplasmic genome types of European potatoes and their effects on complex agronomic traits. BMC Plant Biol., 2015, 15: 162-178 (doi: 10.1186/s12870015-0545-y).

29. Cipar M.S., Peloquin S.J., Hougas R.W. Haploidy and the identification of selfincompatibility alleles in cultivated diploid species. Can. J. Genet. Cytol., 1967, 9: 511-518 (doi: 10.1139/g67-055).

30. Anos he nko B.Yu. Prediction of compatibility between diploid potato varieties. Abstr. of $13^{\text {th }}$ Triennial EAPR Conf. Wageningen, NL, 1996: 518-519.

31. Olsder J., Hermsen J.G.Th. Genetics of self-compatibility in dihaploids of Solanum tuberosum L. 1. Breeding behavior of two self-compatible dihaploids. Euphytica, 1976, 25(3): 597 607 (doi: 10.1007/BF00041597).

32. Cipar M.S., Peloquin S.J., Hougas R.W. Variability in the expression of selfincompatibility in tuber-bearing diploid Solanum species. Am. Potato J., 1964, 41: 155-162 (doi: 10.1007/BF02855317).

33. Hosaka K., Hanne man R.E., Jr. Genetics of self-compatibility in a self-incompatible wild diploid potato species Solanum chacoense. 1. Detection of an S locus inhibitor (Sli) gene. Euphytica, 1998, 99: 191-197 (doi: 10.1023/A:1018353613431).

34. Lindhout P., Meijer D., Schtte T., Hutten R., Visser R., van Eck H. Towards $\mathrm{F}_{1}$ hybrid seed potato breeding. Potato Res., 2011, 54: 301-312 (doi: 10.1007/s11540-011-9196-z).

35. Yermishin A.P. The development of initial parental material for breeding disease resistant potatoes at the diploid level. Plant Breeding and Seed Science, 2000, 44: 105-115.

36. Luksha V.I., Savchuk A.V., Voronkova E.V., Ermishin A.P. Kartofelevodstvo (Minsk), 2010, 17: 137-148 (in Russ.).

37. R a m an na M.S. A re-examination of the mechanisms of $2 n$-gamete formation in potato and its implications for breeding. Euphytica, 1979, 28: 537-561 (doi: 10.1007/BF00038921).

38. Mok D.W.S., Peloquin S.J. The inheritance of three mechanisms of diplandroid ( $2 n$ pollen) formation in diploid potatoes. Heredity, 1975, 35: 295-302 (doi: 10.1038/hdy.1975.100).

39. Podlisskikh V.E., Ankudo T.M., Anoshenko B.Yu. Tsitologiya, 2002, 44: 996-1003 (in Russ.).

40. Hermsen J.G.Th. Mechanisms and genetic implications of 2 -gamete formation. Iowa State 
J. Research, 1984, 58: 421-434.

41. B ani-Aameur F., Laurer F.I., Veilleux R.E. Frequency of $2 n$ pollen in diploid hybrids between Solanum phureja and Solanum chacoense. Potato Res., 1992, 35: 161-172 (doi: 10.1007/BF02357610).

42. J a cobsen E. Diplandroid formation and its importance for the seed set in $4 \times \times 2 \times$ crosses in potato. Z. Pflanzenzuchtg, 1980, 84: 240-249.

43. Ortiz R., Peloquin S.J. Recurrent selection for $2 n$ gamete production in $2 \times$ potatoes. $J$. Genet. Breed., 1992, 46: 383-390.

44. Mooney J., Peloquin S.J. Phenotypic recurrent selection for $2 n$ pollen frequency. Am. Potato J., 1992, 69: 599.

45. Ermis hin A.P. Molekulyarnaya i prikladnaya genetika (Minsk), 2013, 15: 39-47 (in Russ.).

46. Galek R., Rurek M., De Jong W., Pietkievicz G., Augustyniak H., SawickaSienkiewicz E. Application of DNA markers linked to the potato $H 1$ gene conferring resistance to pathotype Ro1 of Globodera rostochiensis. J. Appl. Genet., 2011, 52: 407-411 (doi: 10.1007/s13353-011-0056-y).

47. Gebhardt C., Bellin D., Henselewski H., Lehmann W., Schwarzfischer J., Valko ne n J.P. Marker-assisted combination of major genes for pathogen resistance in potato. Theor. Appl. Genet., 2006, 112: 1458-1464 (doi: 10.1007/s00122-006-0248-8).

48. Kasai K., Morikawa Y., Sorri V.A., Valkonen J.P., Gebhardt C., Watanabe K.N. Development of SCAR markers to the PVY resistance gene $R y_{a d g}$ based on a common feature of plant disease resistance genes. Genome, 2000, 43: 1-8 (doi: 10.1139/gen-43-1-1).

49. Almekinders C.J.M., Chujoy E., Thiele G. The use of true potato seeds as a pro-poor technology: the efforts of an International Agricultural Research Institute to innovating potato production. Potato Res., 2009, 52: 275-293 (doi: 10.1007/s11540-009-9142-5).

50. Jansky S.H., Charkowski A.O., Douches D.S., Gusmini G., Richael C., Bethke P.C., Spooner D.M., Novy R.G., De Jong H., De Jong W.S., Bamberg J..B., Thompson A.L., Bizimungu B., Holm D.G., Brown C.R., Hay ne s K.G., S a thuvalli V.R., Ve ille ux R.E., Mille r C., Jr., B rad e e n J.M., Ji a ng J.M. Reinventing potato as a diploid inbred line-based crop. Crop Sci., 2016, 56: 14121422 (doi: 10.2135/cropsci2015.12.0740).

51. KWS to fully focus on hybrid potato breeding and divest its conventional seed potato business. Available http://kws.com/aw/KWS/company-info/Potatoes/News-Articles/-hjqx/KWS-to-fullyfocus-on-hybrid-potato-bree/. No date. 